\title{
Testy oceniające drożność trąbki słuchowej w codziennej praktyce audiologicznej
}

\section{Eustachian Tube Function Test in audiological practice}

\author{
Edyta Piłka ${ }^{1}$, Paweł Dobrzyński \\ ${ }^{1}$ Instytut Fizjologii i Patologii Słuchu, Światowe Centrum Słuchu, Zakład Audiologii Eksperymentalnej, \\ Warszawa/Kajetany \\ ${ }^{2}$ Centralny Szpital Kliniczny MSW, Klinika Otolaryngologii, Warszawa
}

Adres autora: Edyta Piłka, Światowe Centrum Słuchu, Zakład Audiologii Eksperymentalnej, ul. Mokra 17, Kajetany, 05-830 Nadarzyn, e-mail: e.pilka@ifps.org.pl

\section{Streszczenie}

Trąbka słuchowa jest chrzęstno-kostnym przewodem łączącym jamę bębenkową z częścią nosową gardła. Jej głównym zadaniem jest wyrównywanie ciśnień między uchem środkowym a częścią nosową gardła oraz drenowanie zawartości jamy bębenkowej do gardła.

\begin{abstract}
Testy oceniające drożność trąbki słuchowej zajmują istotne miejsce w praktyce audiologicznej. Niektóre z nich wykonywane są przy użyciu mostka impedancyjnego. Istotą tych testów jest ocena przesunięć wykresu krzywej tympanometrycznej wzdłuż osi odciętych układu, będących konsekwencją zmian ciśnienia powietrza w obrębie ucha środkowego.
\end{abstract}

Słowa kluczowe: test drożności trąbki słuchowej • tympanometria • trąbka słuchowa

\begin{abstract}
The Eustachian tube is a cartilaginous-bony canal linking the tympanic cavity with the nasopharynx. Its main function is to equalize pressure between the middle ear and the nasopharynx and to drain mucus from the middle ear cavity.

Assessment of patency of the Eustachian tube is an important element of audiological practice. Some of these tests are performed using the impedance bridge. They consist in the evaluation of shifts of the tympanometric curve along the $\mathrm{x}$-axis resulting from the changes of air pressure in the middle ear.
\end{abstract}

Key words: Eustachian Tube Function Test • tympanometry • Eustachian tube

\section{Wstęp}

Trąbka słuchowa (ang. Eustachian tube, ET) jest elementem anatomicznym łączącym ucho środkowe z nosogardłem. Zbudowana jest z części kostnej i chrzęstnej oraz mięśni (rycina 1) - napinacza podniebienia miękkiego i napinacza błony bębenkowej. Oba mięśnie są unerwione przez nerw trójdzielny [1-5].

Najważniejszym zadaniem ET jest wyrównywanie ciśnienia pomiędzy uchem środkowym a częścią nosową gardła oraz drenowanie zawartości jamy bębenkowej do gardła. Odbywa się to poprzez otwieranie i zamykanie trąbki słuchowej w jej części chrzęstnej. Prawidłowe otwieranie się ET związane jest głównie z czynnością mięśnia napinacza podniebienia miękkiego [1,6-13]. Właściwie funkcjonująca trąbka słuchowa, poprzez zapewnienie optymalnego położenia błony bębenkowej, warunkuje prawidłową transmisję dźwięków z ucha środkowego do ucha wewnętrznego i zapobiega powstawaniu stanów zapalnych ucha środkowego (ang. Otitis Media with Effusion, OME) [14,15]. Niezdiagnozowany OME może prowadzić do czasowych lub stałych przewodzeniowych ubytków słuchu [16-18]. Określenie czynności trąbki słuchowej przed zabiegami operacyjnymi w uchu środkowym często decyduje o powodzeniu leczenia lub jego braku $[19,20]$.

Zaburzenia w funkcjonowaniu ET mogą być spowodowane wirusowymi infekcjami górnych dróg oddechowych, niewydolnością mięśni podniebienia w wadach rozszczepowych czy u osób z zespołem Downa, alergicznymi nieżytami nosa, polipami nosa, skrzywieniem przegrody nosowej [21-24], nowotworami nosogardła [25,26] czy przerośnięciem migdałka gardłowego $[27,28]$. 


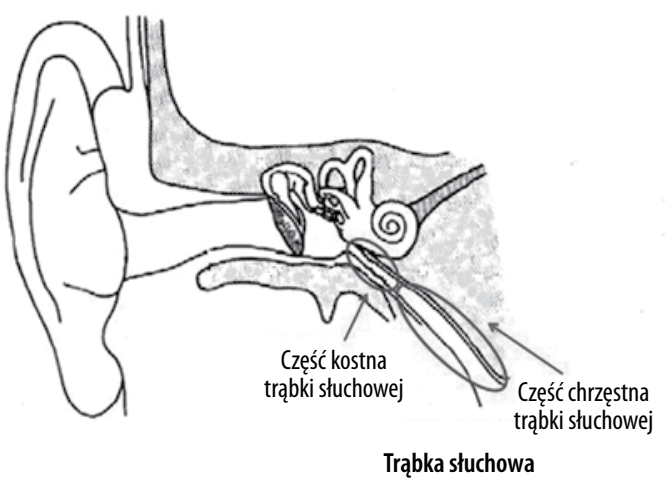

Rycina 1. Schemat ucha z wyszczególnieniem części kostnej i chrzęstnej trąbki słuchowej [1]

Figure 1. Diagram of an ear showing the bony and the cartilaginous part of the Eustachian tube [1]

Celem pracy jest przedstawienie procedury wykonywania podstawowych testów oceniających drożność trąbki słuchowej oraz omówienie interpretacji otrzymanych wyników.

\section{Ocena drożności trąbki słuchowej}

Najczęściej do oceny drożności ET stosuje się tympanometrię, jeden $\mathrm{z}$ testów audiometrii impedancyjnej. Krzywe tympanometryczne klasyfikowane są według kryterium opracowanego przez Jergera i Lidena [29,30]. Zgodnie ze wspomnianym podziałem tympanogramów o niedrożności ET mówimy wówczas, gdy wartość podatności jest prawidłowa, natomiast tympanogram jest przesunięty w kierunku ciśnień ujemnych (typ C - rycina 2). Dysfunkcja trąbki słuchowej może współwystępować z patologią ucha środkowego $[29,30]$.

U pacjentów, którzy zgłaszają dolegliwości związane z nieprawidłowym funkcjonowaniem ET (uczucie zatkania lub pełność w uchu, osłabienie słuchu, szum), bez zmienionego obrazu ujścia gardłowego trąbki w badaniu fiberoskopowym, należy wykonać dodatkowe testy tympanometryczne. Ważna jest wówczas ocena czynnościowa mięśni otwierających ujścia gardłowe, a nie ocena funkcji samej trąbki słuchowej [31].

Istotą testów oceniających drożność ET (ang. Eustachian Tube Function Test) jest ocena przesunięć wykresu krzywej tympanometrycznej wzdłuż osi odciętych układu, będących konsekwencją zmian ciśnienia powietrza w obrębie ucha środkowego [32].

Procedura wykonania testu Williams oceniającego drożność trąbki słuchowej przy zachowanej błonie bębenkowej [32-34]

Chcąc sprawdzić drożność trąbki słuchowej z zachowaną błoną bębenkową, należy wykonać test Williams, pozwalający ocenić sprawność barofunkcji trąbki słuchowej. Wykonanie testu drożności trąbki słuchowej obejmuje trzy etapy, podczas których wymagana jest odpowiednia współpraca pacjenta.

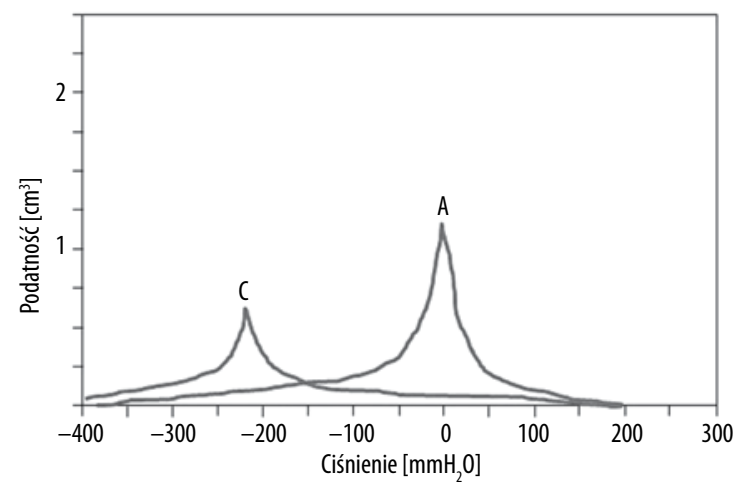

Rycina 2. Tympanogram typu C - niedrożność trąbki słuchowej w odniesieniu do tympanogramu A (prawidłowa funkcja ucha środkowego) $[29,30]$

Figure 2. Type C tympanogram - occluded Eustachian tube, compared to Type A tympanogram (correctly functioning middle ear) $[29,30]$

Etap I - wyznaczenie ciśnienia w jamie bębenkowej - standardowe badanie tympanometryczne.

Etap II - wykonanie próby Toynbee'ego - przełknięcie śliny przy jednoczesnym zatkaniu nosa powoduje zasysanie powietrza $z$ jamy bębenkowej do gardła i jamy ustnej, co prowadzi do wytworzenia ujemnego ciśnienia w jamach bębenkowych. Konsekwencja tego jest przesunięcie krzywej tympanometrycznej w lewo - w kierunku ujemnych wartości ciśnienia.

Etap III - wykonanie próby Valsalvy - przemieszczenie powietrza do jam bębenkowych, powodowane wydechem przy zamkniętych ustach i zatkanym nosie, przesuwa krzywą tympanometryczną w kierunku dodatnich wartości ciśnienia (w prawo). Przy silnym przemieszczeniu powietrza może nastąpić wypłaszczenie krzywej i ponowne uruchomienie pompy w tympanometrze pokaże przesuniętą krzywą (o ile jest zachowana barofunkcja trąbki całkowita lub częściowa).

Kolejność wykonywania prób z etapu II i III może być zamieniona. Należy jednak pamiętać o prawidłowym oznaczeniu wyniku w celu właściwej interpretacji.

Interpretacja testu oceniającego drożność trąbki słuchowej przy zachowanej błonie bębenkowej $[33,34]$

Na rycinie 3 przedstawiono wynik testu oceniającego drożność trąbki słuchowej przy zachowanej błonie bębenkowej w kolejnych trzech etapach testu Williams dla prawidłowo funkcjonującej ET. Ciśnienie $\mathrm{P}_{1}$ odpowiada ciśnieniu w jamie bębenkowej podczas rejestracji standardowego tympanogramu, $\mathrm{P}_{2}$ po przełknięciu śliny (test Toynbee'ego), natomiast $\mathrm{P}_{3}$ po wdmuchnięciu powietrza - test Valsalvy. O prawidłowym wyniku testu ETF możemy mówić wówczas, gdy różnica pomiędzy $\mathrm{P}_{1}$ i $\mathrm{P}_{2}$ mieści się $\mathrm{w}$ granicach $\pm 25 \mathrm{daPa}[33]$.

Biswas [34] w swojej pracy pokazuje, iż w uchu z prawidłowo funkcjonującą trąbką słuchową przesunięcie tympanogramu w stronę ciśnień ujemnych w stosunku do 


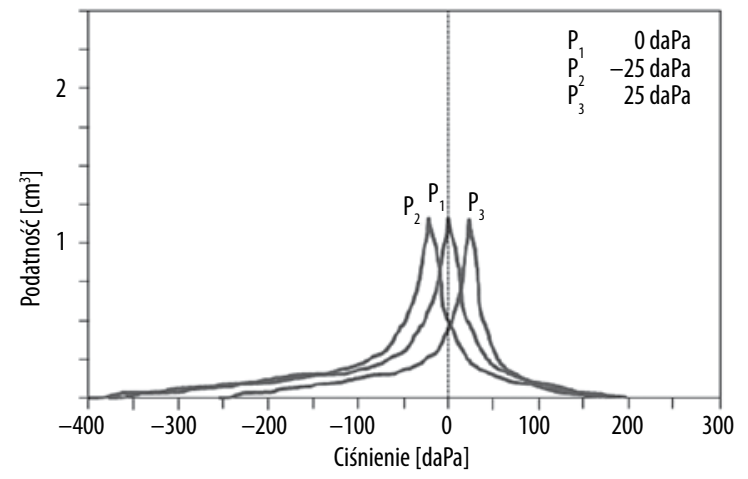

Rycina 3. Test Williams (zachowana błona bębenkowa) - ucho z prawidłową drożnością trąbki słuchowej - różnica ciśnień między $P_{1}$ i $P_{2}$ w granicach \pm 25 daPa [33]

Figure 3. ETF Test (preserved tympanic membrane) - normal Eustachian tube patency - difference of pressure between $P_{1}$ and $\mathrm{P}_{2}$ within $\pm 25 \mathrm{daPa}$ [33]

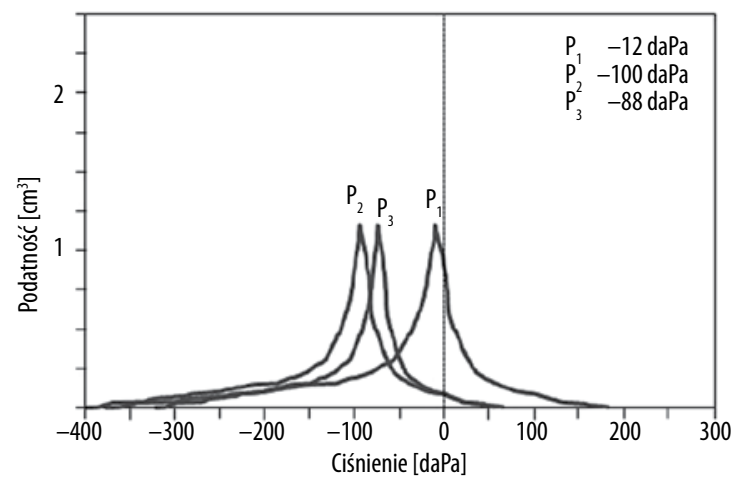

Rycina 4. Test Williams (zachowana błona bębenkowa) - ucho z częściowo zaburzoną drożnością trąbki słuchowej [34]

Figure 4. ETF Test (preserved tympanic membrane) - partially occluded Eustachian tube [34]

tympanogramu wyjściowego może być znacznie większe, nawet w granicach $100 \mathrm{daPa}$.

Na rycinie 4 przedstawiono wynik testu ETF dla ucha z częściowo zaburzoną drożnością trąbki. Przy przełknięciu śliny krzywa tympanometryczna $\left(\mathrm{P}_{2}\right)$ przesuwa się $\mathrm{w}$ kierunku wartości ujemnych, jednakże po wdmuchaniu powietrza $\left(\mathrm{P}_{3}\right)$ przy zatkanym nosie nie następuje znaczące przesunięcie w kierunku wartości dodatnich [34].

Na rycinie 5 przedstawiono kolejny wynik testu ETF z częściowo zaburzoną pracą trąbki słuchowej. Przy przełknięciu śliny krzywa tympanometryczna $\left(\mathrm{P}_{2}\right)$ nie przesuwa się w kierunku wartości ujemnych. Jednocześnie po wdmuchaniu powietrza przy zatkanym nosie i ustach tympanogram $\left(\mathrm{P}_{3}\right)$ znacząco przesuwa się $\mathrm{w}$ kierunku wartości dodatnich [34].

Kolejna rycina (rycina 6) przedstawia nieprawidłowy wynik testu ETF z całkowicie niedrożną trąbką słuchową. Charakteryzuje się to tym, że przy przełknięciu śliny krzywa tympanometryczna $\left(\mathrm{P}_{2}\right)$ nie przesuwa się w kierunku wartości ujemnych. Jest $\mathrm{w}$ tym samym miejscu co standardowy $\left(\mathrm{P}_{1}\right)$ tympanogram. Natomiast po wdmuchaniu

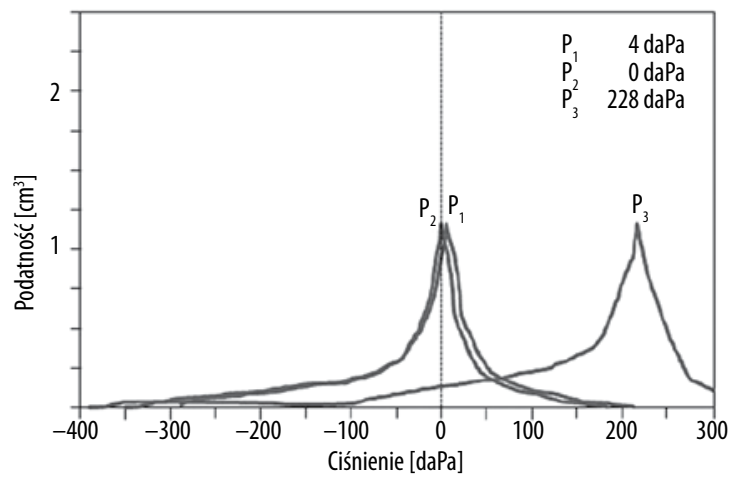

Rycina 5. Test Williams (zachowana błona bębenkowa) - ucho z częściowo zaburzoną drożnością trąbki słuchowej

Figure 5. ETF Test (preserved tympanic membrane) - partially occluded Eustachian tube

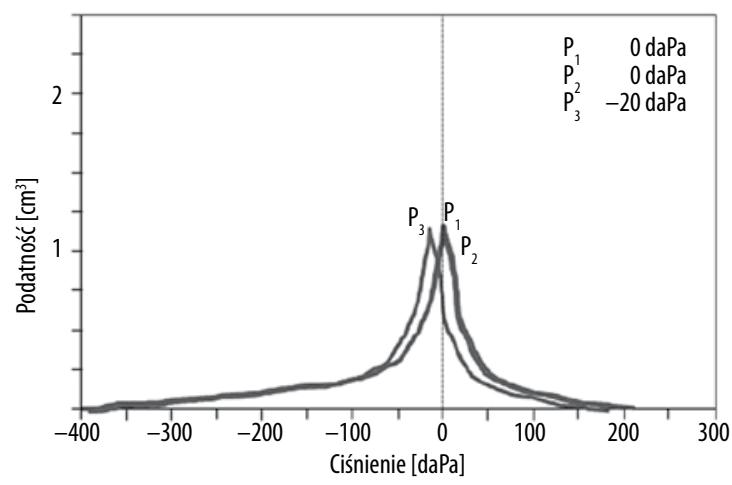

Rycina 6. Test Williams (zachowana błona bębenkowa) - ucho z niedrożną trąbką słuchową [34]

Figure 6. ETF Test (preserved tympanic membrane) - occluded Eustachian tube [34]

powietrza przy zatkanym nosie tympanogram $\left(\mathrm{P}_{3}\right)$ przesuwa się nieznacznie w kierunku wartości ujemnych [34].

Procedura wykonania testu drożności trąbki słuchowej przy perforacji błony bębenkowej [34]

Chcąc ocenić drożność trąbki słuchowej przy perforacji błony bębenkowej, należy wykonać test Toynbee'ego. Zadaniem pacjenta podczas testu jest rytmiczne przełykanie wody. Oceniane jest wówczas ciśnienie przy otwartej trąbce słuchowej $\left(\mathrm{O}_{1}, \mathrm{O}_{2}, \mathrm{O}_{3}\right)$ oraz ciśnienie przy zamkniętej trąbce słuchowej $\left(\mathrm{C}_{1}, \mathrm{C}_{2}, \mathrm{C}_{3}\right)$. Wynik przedstawiony jest w postaci „schodków” (rycina 7 ).

Interpretacja testu oceniającego drożność trąbki słuchowej przy perforacji błony bębenkowej [34]

Na rycinie 8 zaprezentowano wynik testu ETF przy perforacji błony bębenkowej przy prawidłowo funkcjonującej trąbce słuchowej. Wynik przedstawiony jest w postaci „schodków”, gdzie ciśnienie otwieranej trąbki słuchowej $\left(\mathrm{O}_{1}, \mathrm{O}_{2}, \mathrm{O}_{3}\right)$ odpowiednio zmienia wartość $\mathrm{w}$ stosunku do ciśnienia zamykanej ET $\left(\mathrm{C}_{1}, \mathrm{C}_{2}, \mathrm{C}_{3}\right)$ podczas przełykania wody przez pacjenta. 


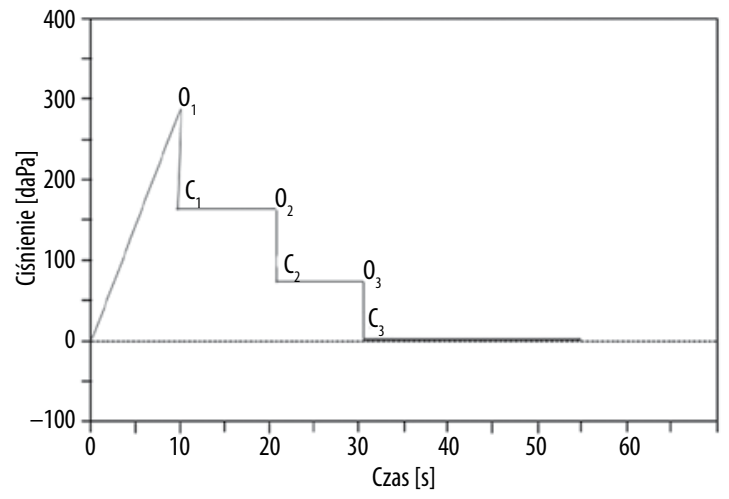

Rycina 7. Test Toynbee'ego (perforacja błony bębenkowej) $-\mathrm{O}_{1}, \mathrm{O}_{2}, \mathrm{O}_{3}$ - ciśnienie przy otwartej trąbce słuchowej; $\mathrm{C}_{1}, \mathrm{C}_{2}$, $\mathrm{C}_{3}$ - ciśnienie przy zamkniętej trąbce słuchowej [34]

Figure 7. Toynbee test (tympanic membrane perforation) $-\mathrm{O}_{1}, \mathrm{O}_{2}, \mathrm{O}_{3}$ - pressure with open Eustachian tube; $\mathrm{C}_{1}, \mathrm{C}_{2}, \mathrm{C}_{3}$ - pressure with closed Eustachian tube [34]

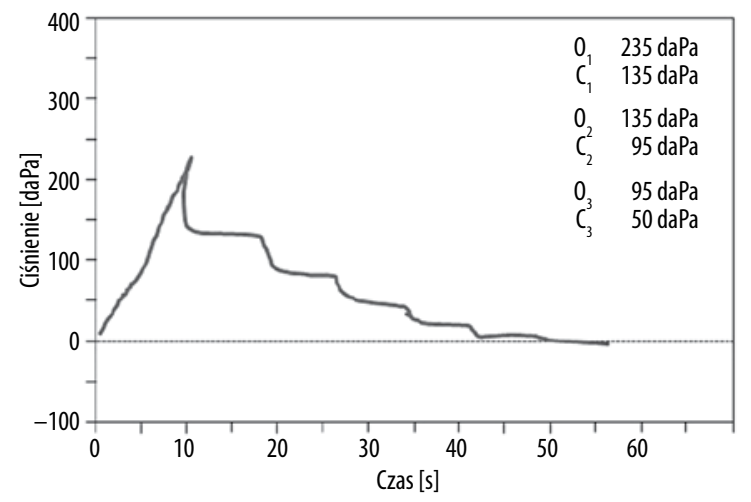

Rycina 8. Test Toynbee'ego (perforacja błony bębenkowej) - ucho z prawidłową drożnością trąbki słuchowej [34]

Figure 8. Toynbee test (tympanic membrane perforation) - patent Eustachian tube [34]

Rycina 9 przedstawia wynik testu ETF przy perforowanej błonie bębenkowej dla ucha z częściowo zaburzoną drożnością trąbki słuchowej. Zachowana jest częściowo forma „schodków”, jednakże ciśnienie przy otwartej i zamkniętej trąbce słuchowej nie zmienia się proporcjonalnie do zbliżania się krzywej tymanometrycznej do 0 [daPa].

Na rycinie 10 przedstawiono wynik dla ucha z perforacją błony bębenkowej z niedrożną trąbką słuchową. Nie zostały zarejestrowane zmiany w ciśnieniu powstającym przy otwieraniu i zamykaniu ET podczas przełykania.

\section{Podsumowanie}

Właściwie funkcjonująca trąbka słuchowa poprzez wyrównanie ciśnienia pomiędzy uchem środkowym a nosogardłem warunkuje prawidłowe funkcjonowanie ucha środkowego. Dodatkowo drenuje zawartość jamy bębenkowej do gardła.

Celem pracy było przedstawienie procedury wykonywania testów oceniających funkcjonalność trąbki słuchowej oraz omówienie interpretacji otrzymanych wyników.

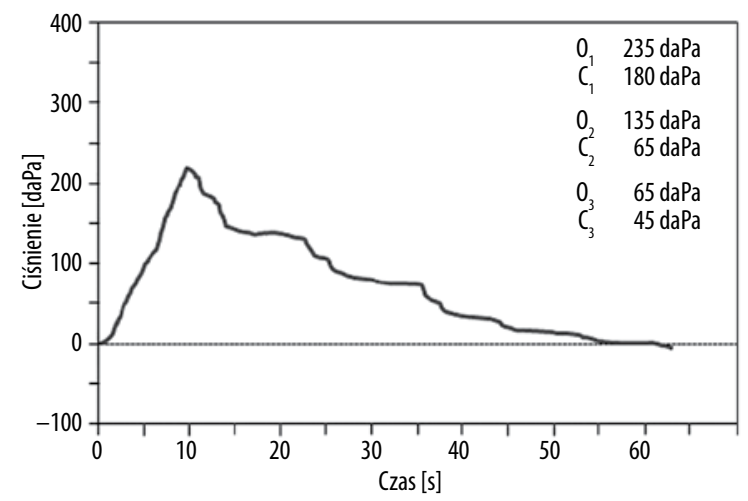

Rycina 9. Test Toynbee'ego (perforacja błony bębenkowej) - ucho z częściowo zaburzoną drożnością trąbki słuchowej [34] Figure 9. Toynbee test (tympanic membrane perforation) - partially occluded Eustachian tube [34]

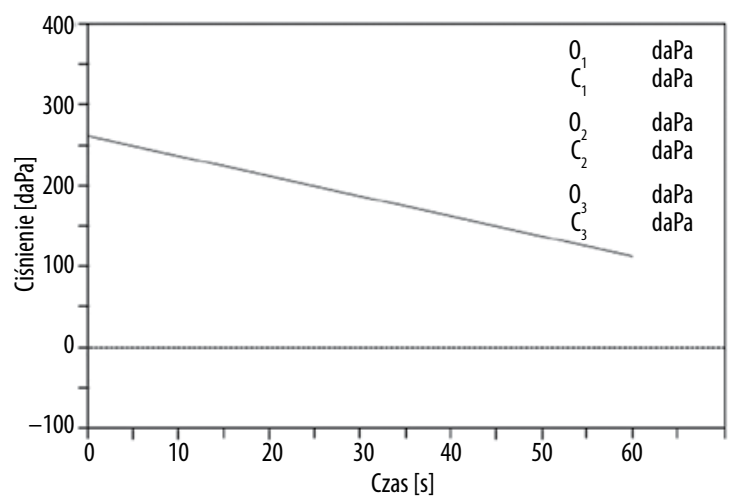

Rycina 10. Test Toynbee'ego (perforacja błony bębenkowej) - ucho z niedrożną trąbką słuchową [34]

Figure 10. Toynbee test (tympanic membrane perforation) - occluded Eustachian tube [34]

Niewątpliwie wiedza na temat funkcjonowania trąbki słuchowej ma ogromne znaczenie przed zabiegami operacyjnymi w uchu środkowym, gdyż często decyduje o powodzeniu podjętego leczenia. Drożność trąbki słuchowej można określić na podstawie badania tympanometrii, oceniając jej wyniki według klasyfikacji Jergera i Lidena. Dodatkową metodą diagnostyczną pozwalającą na wizualną ocenę ujść gardłowych trąbek słuchowych jest badanie nosogardła giętkim endoskopem (wideofiberoskopia). U pacjentów, którzy zgłaszają problem z zatykaniem ucha i u których nie stwierdza się zmian w obrazie fiberoskopowym, wykonywane są, oprócz standardowej tympanometrii, testy oceniające funkcjonalność trąbki słuchowej. Ważna jest zatem umiejętność właściwej interpretacji otrzymanych wyników.

Publikacja powstała $w$ związku z realizacja projektu pn. „Zintegrowany system narzędzi do diagnostyki i telerehabilitacji schorzeń narządów zmystów (słuchu, wzroku, mowy, równowagi, smaku, powonienia)" INNOSENSE, wspólfinansowanego przez Narodowe Centrum Badań i Rozwoju w ramach Programu STRATEGMED. 


\section{Piśmiennictwo:}

1. Bochenek A, Reicher M. Anatomia człowieka. Warszawa: PZWL; 2003, V.

2. Bremond A, Magnan J, Chays A, de Gasquet R. Endoscopy of the Eustachian tube. 1st evaluation. Ann Otolaryngol Chir Cervicofac, 1990; 107(1): 15-9.

3. Rood SR, Doyle WJ. Anatomy: introduction. Ann Otol Rhinol Laryngol, 1985; 120(Suppl. 94): 6-8.

4. Poe DKO. Endoscopic diagnoses of Eustachian tube dysfunction. W: Glasscock ME, Gulya AJ, red. Glasscock-Shambaugh Surgery of the Ear, 2002.

5. van der Avoort SJ, van Heerbeek N, Zielhuis GA i wsp. Sonotubometry: Eustachian tube ventilator function test: a state-of-the-art review. Otol Neurotol, 2005; 26: 538-43.

6. Bluestone CD. Impact of evolution on the Eustachian tube. Laryngoscope, 2008; 118: 522-7.

7. Narożny W. Anatomia narządu słuchu. W: Śliwińska-Kowalska M, red. Audiologia kliniczna. Łódź: Mediton; 2005, s. 6.

8. Chauhan B, Chauhan K. A comparative study of Eustachian tube functions in normal and diseased ears with tympanometry and videonasopharyngoscopy. Indian J Otolaryngol Head Neck Surg, 2013; 65(Suppl. 3): 468-76.

9. Kumazawa T, Iwano T, Ushiro K, Kinoshita T, Hamada E, Kaneko A. Eustachian tube function tests and their diagnostic potential in normal and diseased ears. Acta Otolaryngol, 1993; 500 (Suppl): 10-3.

10. Joshi SS, Jagade M, Agarwal S, Ahire D. Tympanometry, a prognostic indicator of myringoplasty with assessment of Eustachian tube function. Int J Otolaryngol Head Neck Surg, 2012; 1: $105-8$.

11. Bluestone CD, Doyle WJ. Anatomy and physiology of Eustachian tube and middle ear related to otitis media. J Allergy Clin Immunol, 1988; 81(5, pt 2): 997-1003.

12. Doyle WJ. Physiology: Introduction. Ann Otol Rhinol Laryngol, 1985; 120 (94 Suppl.): 20-1.

13. Magnuson B. How to treat tubal malfunction? W: Sade J, red. The Eustachian tube and middle ear diseases. Clinical Aspects. Amsterdam - Milano - New York: Kugler\&Ghedini Publicalion; 1991, 89-291.

14. Maroldi R, Farina D, Palvarini L i wsp. Computed tomography and magnetic resonance imaging of pathologic conditions of the middle ear. Eur J Radiol, 2001; 40: 78-93.

15. Su CY. Valve section of the Eustachian tube. J Laryngol Otol, 1995; 109: 486-90.

16. Kilic A, Baysal E, Karatas E, Baglam T, Duruc C, Deniz M i wsp. The role of high frequency tympanometry in newborn hearing screening programme. Eur Rev Med Pharmacol Sci, 2012; 16: 220-3.

17. Shahnaz N, Miranda T, Polka L. Multifrequency tympanometry in neonatal intensive care unit and well babies. J Am Acad Audiol, 2008; 19: 392-418.

18. Hueb MM, Goycoolea MV. Experimental evidence suggestive of early intervention in mucoid otitis media. Acta Oto-Laryngologica, 2009; 129: 444-8.
19. Mandel EM, Swarts JD, Casselbrant ML, Tekely KK, Richert BC, Seroky JT i wsp. Eustachian tube function as a predictor of the recurrence of middle ear effusion in children. Laryngoscope, 2013; 123(9): 2285-90.

20. McDonald MH, Hoffman MR, Gentry LR, Jiang JJ. New insights into mechanism of Eustachian tube ventilation based on cine computed tomography images. Eur Arch Otorhinolaryngol, 2012; 269(8): 1901-7.

21. Friedman RA, Doyle WJ, Casselbrant ML, Bluestone C, Fireman P. Immunologic-mediated Eustachian tube obstruction: a double-blind crossover study. J Allergy Clin Immunol, 1983; 71(5): 442-7.

22. Heavner SB, Hardy SM, White DR, McQueen CT, Prazma J, Pillsbury HC III. Function of the Eustachian tube after weekly exposure to pepsin/hydrochloric acid. Otolaryngol Head Neck Surg, 2001; 125(3): 123-9.

23. McBride TP, Doyle WJ, Hayden FG, Gwaltney JM Jr. Alterations of the Eustachian tube, middle ear, and nose in rhinovirus infection. Arch Otolaryngol Head Neck Surg, 1989; 115(9): 1054-9.

24. Bernstein JM. Role of allergy in Eustachian tube blockage and otitis media with effusion: a review. Otolaryngol Head Neck Surg, 1996; 114(4): 562-8.

25. Yang MS, Chen CC, Cheng YY, Hung HC, Chen WH, Lee MC i wsp. Nasopharyngeal carcinoma spreading along the Eustachian tube: the imaging appearance. J Chin Med Assoc, 2004; 67(4): 200-3.

26. Low WK, Lim TA, Fan YF, Balakrishnan A. Pathogenesis of middle-ear effusion in nasopharyngeal carcinoma: a new perspective. J Laryngol Otol, 1997; 111(5): 431-4.

27. Takahashi H, Miura M, Honjo I, Fujita A. Cause of Eustachian tube constriction during swallowing in patients with otitis media with effusion. Ann Otol Rhinol Laryngol, 1996; 105(9): 724-8.

28. Bluestone CD. Eustachian tube structure, function, role in otitis media. Hamilton, Ontario, Canada: BC Decker Inc., 2005.

29. Jerger J. Clinical experience with impedance audiometry. Arch Otoloaryngol, 1970; 92: 311-24.

30. Liden G, Harford E, Hallen O. Automatic tympanometry in clinical practice. Audiology, 1974; 13: 126-39.

31. Markowska R, Szkiełkowska A, Ratyńska J, Barański B. Ocena czynnościowych zaburzeń trąbek słuchowych. Audiofonologia, 2004; 26: 73-5.

32. Mikołajewski R. Wprowadzenie do audiometrii impedancyjnej. Warszawa, 1994.

33. Williams PS. A tympanometric pressure swallow test for assessment of Eustachian tube function. Ann Otol, 1975; 84: 339-43.

34. Biswas A. Eustachian tube function test: a new dimension in the management of CSOM. Indian J Otolaryngol Head Neck Surg, 1999; 51(2): 14-22. 